\title{
Characterization of halotolerant Thermus isolates from shallow marine hot springs on S. Miguel, Azores
}

\author{
Célia M. Manaia and Milton S. Da Costa* \\ Centro de Biologia Celular, Departamento de Zoologia, and Instituto de Investigação da Água, Universidade de Coimbra, \\ 3049 Coimbra Codex, Portugal
}

(Received 25 March 1991; revised 26 June 1991; accepted 16 July 1991)

\begin{abstract}
Fifteen yellow-pigmented halotolerant Thermus strains from shallow marine hot springs on a beach on S. Miguel, Azores, several isolates from terrestrial hot springs on S. Miguel and mainland Portugal, and four reference strains were subjected to a numerical taxonomy study based on 61 characters by unweighted average linkage analysis (UPGMA) using the simple matching $\left(S_{\mathrm{SM}}\right)$ coefficient. This analysis produced four clusters at the $75 \%$ similarity level. Two clusters, $A$ and $B$, were composed of halotolerant strains from the beach hot springs and one strain isolated inland, all of which also grew at $80^{\circ} \mathrm{C}$; cluster $\mathrm{C}$ was composed of strains from one hot spring in mainland Portugal, while cluster $D$ was composed of terrestrial strains from the Furnas area of $S$. Miguel. 'T. thermophilus' HB-8 and Thermus B were also halotolerant, also grew at $80^{\circ} \mathrm{C}$, and formed a large group at the $61 \%$ similarity level with the strains of clusters $A$ and $B$.
\end{abstract}

\section{Introduction}

Terrestrial hydrothermal areas are common geological features throughout the world, but shallow hydrothermally heated marine sea floors are very rare. Most of the organisms reported from these marine environments are extremely thermophilic anaerobic archaeobacteria (Fiala \& Stetter, 1986; Zillig et al., 1987; 1990) and eubacteria of the genus Thermotoga (Huber et al., 1986; Jannasch et al., 1988). Other, more moderate thermophilic eubacteria of the genus Thermus (Kristjansson et al., 1986; Hjorleifsdottir et al., 1989; Hudson et al., 1989) and Rhodothermus marinus (Alfredsson et al., 1988) have also been isolated from neutral to alkaline shallow marine hot springs where they may constitute major aerobic populations.

The high-temperature strains of the genus Thermus, with optimum growth temperatures between $70^{\circ} \mathrm{C}$ and $75^{\circ} \mathrm{C}$, have a worldwide distribution in neutral to alkaline terrestrial hot springs (Munster et al., 1986; Hudson et al., 1989, Santos et al., 1989) and artificial environments (Pask-Hughes \& Williams, 1975; Stramer \& Starzyk, 1981). The small number of marine isolates examined are markedly more halotolerant than the vast majority of high-temperature Thermus, but share several phenotypic characteristics with the terrestrial organisms. The relationship of the marine strains to $T$. aquaticus (Brock \& Freeze, 1969) and T. filiformis (Hudson et al.,
1987), or to other, possibly unrecognized species, is unknown.

In this study we describe the phenotypic characteristics of several Thermus isolates from the coastal marine vents at Ribeira Quente, S. Miguel. These strains are compared to terrestrial strains isolated nearby, to isolates from mainland Portugal and to several reference strains.

\section{Methods}

Sources and isolation of strains. Water samples were collected from small depressions dug in the sand during low tide from four sites within an area of about $500 \mathrm{~m}^{2}$ at the sandy beach at Ribeira Quente on S. Miguel, Azores. Water samples were also collected from terrestrial hot springs about $10 \mathrm{~km}$ inland in the Furnas area of S. Miguel, and at $S$. Pedro do Sul in central mainland Portugal. Temperature, $\mathrm{pH}$ and salinity (Yellow Spring Inst. Co., model 33) were measured at the time of sampling (Table 1).

Water samples were filtered within $6 \mathrm{~h}$, through Gelman type GN-6 $(0.45 \mu \mathrm{m}$ pore size) membrane filters, placed on Thermus agar (Brock, 1978) and incubated for $3 \mathrm{~d}$ at $70^{\circ} \mathrm{C}$ in plastic bags. Representative yellow-pigmented colonies were isolated, transferred to Thermus agar for purification and stored at $-80^{\circ} \mathrm{C}$ in Thermus medium with $15 \%(\mathrm{v} / \mathrm{v})$ glycerol.

T. aquaticus YT-1 (ATCC 25104t), 'T. thermophilus' HB-8 (ATCC 27634) and T. filiformis (ATCC 43280') were obtained from the American Type Culture Collection. Strain B (NCIMB 11247) was kindly donated by R. A. D. Williams; strains SPS-17 and RQ-1 were described previously (Santos et al., 1989; Williams, 1989).

Characters tested. Most phenotypic characteristics were examined as applied by Hudson et al. (1986) and Santos et al. (1989) in Thermus medium $(5.0 \mathrm{ml})$ or Thermus agar incubated at $70^{\circ} \mathrm{C}$ for up to $7 \mathrm{~d}$. 
Table 1. Origin of isolates arranged by cluster

\begin{tabular}{clllll}
\hline \hline Cluster & \multicolumn{1}{c}{ Strain } & pH & ${ }^{\circ}$ C & $\begin{array}{c}\text { Salinity } \\
(\%)\end{array}$ & Sample location \\
\hline A & PRQ-14 & $7 \cdot 2$ & 72 & 21 & Beach, Ribeira Quente, S. Miguel \\
A & PRQ-16 & $7 \cdot 2$ & 72 & 21 & Beach, Ribeira Quente, S. Miguel \\
A & PRQ-21 & $7 \cdot 1$ & $74 \cdot 5$ & 29 & Beach, Ribeira Quente, S. Miguel \\
A & PRQ-24 & $7 \cdot 0$ & 55 & 29 & Beach, Ribeira Quente, S. Miguel \\
A & PRQ-26 & $7 \cdot 0$ & 55 & 29 & Beach, Ribeira Quente, S. Miguel \\
A & PRQ-25 & $7 \cdot 0$ & 55 & 29 & Beach, Ribeira Quente, S. Miguel \\
A & PRQ-23 & $7 \cdot 0$ & 55 & 29 & Beach, Ribeira Quente, S. Miguel \\
A & PRQ-27 & $7 \cdot 0$ & 55 & 29 & Beach, Ribeira Quente, S. Miguel \\
B & PRQ-15 & $7 \cdot 2$ & 72 & 21 & Beach, Ribeira Quente, S. Miguel \\
B & PRQ-30 & $6 \cdot 8$ & 40 & 30 & Beach, Ribeira Quente, S. Miguel \\
B & PRQ-31 & $6 \cdot 8$ & 40 & 30 & Beach, Ribeira Quente, S. Miguel \\
B & RQ-1 & NA & 70 & NA & Cliff, Ribeira Quente, S. Miguel \\
B & PRQ-17 & $7 \cdot 1$ & $74 \cdot 5$ & 29 & Beach, Ribeira Quente, S. Miguel \\
B & PRQ-18 & $7 \cdot 1$ & $74 \cdot 5$ & 29 & Beach, Ribeira Quente, S. Miguel \\
B & PRQ-28 & $6 \cdot 8$ & 40 & 30 & Beach, Ribeira Quente, S. Miguel \\
B & PRQ-19 & $7 \cdot 1$ & $74 \cdot:$ & 29 & Beach, Ribeira Quente, S. Miguel \\
- & B & $8 \cdot 9$ & 82 & NA & Hruni, Iceland \\
- & 'T. thermophilus' HB-8 & $6 \cdot 3$ & 80 & NA & Mine, Japan \\
- & T. aquaticus YT-1 & NA & $71 \cdot 5$ & NA & Yellowstone Park, USA \\
C & SPS-17 & $8 \cdot 5$ & 50 & NA & S. Pedro do Sul \\
C & SPS-21 & $8 \cdot 3$ & $70 \cdot 5$ & NA & S. Pedro do Sul \\
C & SPS-20 & $8 \cdot 3$ & $70 \cdot 5$ & NA & S. Pedro do Sul \\
D & T. filiformis & $7 \cdot 3$ & 82 & NA & North Island, New Zealand \\
D & ECG-1 & $8 \cdot 5$ & 75 & NA & Runoff, Caldeira Grande, S. Miguel \\
D & CB-4 & $7 \cdot 5$ & 90 & NA & Caldeira da Barrela, S. Miguel \\
D & ECG-2 & $8 \cdot 5$ & 75 & NA & Runoff, Caldeira Grande, S. Miguel \\
D & CB-3 & $7 \cdot 5$ & 90 & NA & Caldeira da Barrela, S. Miguel \\
D & ECB-6 & $8 \cdot 4$ & 75 & NA & Runoff, Caldeira da Barrela, S. Miguel \\
\hline \hline
\end{tabular}

NA, Not available.

Some tests were modified as follows: Casein hydrolysis was performed with $5.0 \%(\mathrm{w} / \mathrm{v})$ skim milk powder (Difco) and $1.5 \%(\mathrm{w} / \mathrm{v})$ agar overlaid on Thermus agar which had been allowed to solidify ( $R$. Sharp, personal communication). The hydrolysis of gelatin was tested in Thermus agar with $0.4 \%$ gelatin (Difco). Cultures were flooded with $\mathrm{HgCl}_{2}-\mathrm{HCl}$ (Smibert \& Krieg, 1981) after incubation of replicate plates for $1 \mathrm{~d}$ or $3 \mathrm{~d}$. The degradation of arbutin was examined in Thermus agar containing $0.5 \%$ filter-sterilized arbutin and $5.0 \mathrm{mg} \mathrm{I^{-1 }}$ ammonium ferric citrate. The degradation of aesculin was tested in Thermus agar supplemented with $0.01 \%$ aesculin and $5.0 \mathrm{mg} \mathrm{l}^{-1}$ ferric citrate. Nitrate reduction was performed in Thermus medium containing only $1.0 \mathrm{~g} \mathrm{l}^{-1} \mathrm{KNO}_{3}$ and $0.25 \%$ agar. Starch hydrolysis was examined in Thermus agar in which tryptone was replaced by $\mathrm{NH}_{4} \mathrm{Cl}$ $(0.05 \%)$ and containing $10.0 \mathrm{~g} \mathrm{l}^{-1}$ soluble starch. Plates were flooded with Lugol's iodine after $5 \mathrm{~d}$ incubation.

Single carbon source utilization was tested in 96-well round bottom culture clusters (Costar). The double strength basal medium consisted of CMD salts (Castenholtz, 1969) adjusted to $\mathrm{pH} 8.2$ and sterilized by autoclaving. Filter-sterilized $\left(\mathrm{NH}_{4}\right)_{2} \mathrm{SO}_{4}\left(0.5 \mathrm{~g} \mathrm{l}^{-1}\right.$ final concentration) was added to cooled medium. Since several strains did not grow or exhibited poor growth in the basal medium a growth factor supplement and an amino acid solution were added to the basal salts- $\left(\mathrm{NH}_{4}\right)_{2} \mathrm{SO}_{4}$ medium (R. Sharp, personal communication). The growth factor supplement, consisted of thiamine, riboflavin, pyridoxine, biotin, folic acid, inositol, nicotinic acid, pantothenic acid, $p$-aminobenzoic acid, cyanocobalamin, adenine, thymine, cytidine, uracil and inosine, each at a final concentration of $40.0 \mu \mathrm{g}^{-1}$. The amino acid solution contained the following L-amino acids: aspartic acid, tyrosine, valine, phenylalanine, lysine, glutamic acid, alanine, asparagine, arginine, tryptophan, cysteine, cystine, serine, leucine, threonine, isoleucine, proline, methionine and histidine, each at a final concentration of $3.5 \mathrm{mg} \mathrm{l}^{-1}$. The inoculum $(1 \mathrm{ml})$ with a turbidity equal to the standard No. 2 of McFarland was added to $15 \mathrm{ml}$ medium and $200 \mu \mathrm{l}$ of this suspension was added to duplicate wells containing $5 \mu \mathrm{l}$ of the appropriate filter-sterilized carbon source at a final concentration of $2.5 \mathrm{~g} \mathrm{l}^{-1}$. Controls with no added carbon source, as well as controls in Thermus medium were also included. Incubation was at $65^{\circ} \mathrm{C}$ for $3 \mathrm{~d}$ (Santos et al., 1989).

Calculation of test error. Five random strains were prepared in duplicate at the beginning of the study, assigned different numbers and tested as separate isolates (Sneath \& Johnson, 1972).

Analysis of results. The phenetic data, consisting of 61 characters scored as plus $(+)$ or minus $(-)$ were analysed using the simple matching $\left(S_{\mathrm{SM}}\right)$ coefficient (Legendre \& Legendre, 1984). Clustering was accomplished by unweighted average linkage analysis (UPGMA) using the Numerical Taxonomy and Multivariate Analysis Program (NTSYS-pc) developed by Rolf (1987).

\section{Results}

\section{Clustering of isolates}

Analysis of the $S_{\mathrm{SM}} /$ UPGMA results indicated that four clusters, labelled A to D, could be defined at the $75 \%$ similarity level (Fig. 1). Error based on mismatches of 


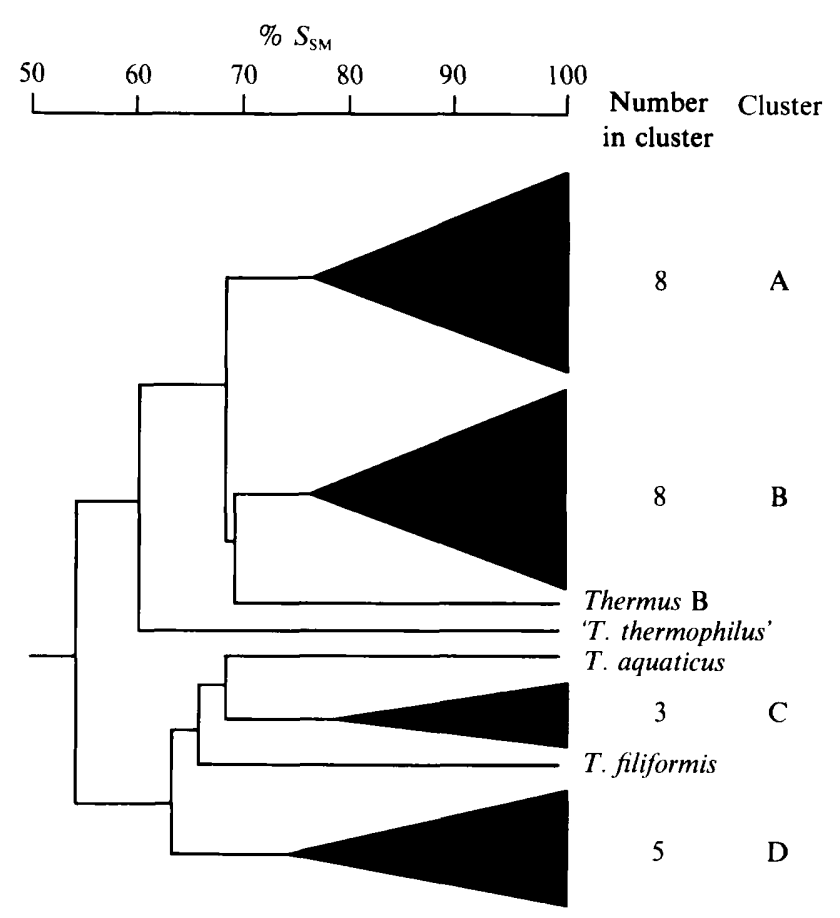

Fig. 1. Dendrogram representing the relationships of the Thermus isolates resulting from the UPGMA analysis based on the $S_{\mathrm{SM}}$ coefficient. The clusters, labelled A to $\mathrm{D}$, were formed at the $75 \%$ level.

results for the duplicate strains was estimated at $4.6 \%$. In addition, $T$. aquaticus YT-1, strain B, 'T. thermophilus' HB-8 and $T$. filiformis did not cluster, at this level, with any of the other organisms.

Clusters A and B were composed of isolates from the beach at Ribeira Quente. Strain RQ-1, isolated from a hot spring about $5 \mathrm{~km}$ inland, was included in cluster $\mathrm{B}$. Cluster $\mathrm{C}$ was composed of the $\mathrm{S}$. Pedro do Sul isolates, while cluster D comprised all isolates from the Furnas area of S. Miguel.

At a lower similarity level (61\%) two large groups were formed; one included all marine isolates and the terrestrial strains RQ-1, B and ' $T$. thermophilus' HB-8 while the other comprised only terrestrial strains.

\section{Characterization of the isolates}

All Thermus strains formed yellow-pigmented colonies, nevertheless the marine isolates of cluster A were distinguished from all other organisms by their deep yellow-orange pigmentation.

All strains from the beach at Ribeira Quente and strains RQ-1, B and HB-8 were halotolerant and grew at $80^{\circ} \mathrm{C}$. These organisms grew in medium with at least $3 \%$ $(\mathrm{w} / \mathrm{v}) \mathrm{NaCl}$, and most also grew in $5 \%(\mathrm{w} / \mathrm{v}) \mathrm{NaCl}-$ containing medium (Table 2). The halotolerance of these organisms was associated with their overall tolerance to $\mathrm{KCl}, \mathrm{CaCl}_{2}, \mathrm{MgCl}_{2}$ and $\mathrm{SrCl}_{2}$.

The halotolerant organisms of clusters $\mathrm{A}$ and $\mathrm{B}$ were generally less proteolytic than the non-halotolerant terrestrial Thermus strains. In contrast, strains of clusters $\mathrm{A}$ and $\mathrm{B}$ degraded $p$-nitrophenyl laurate within $7 \mathrm{~h}$, while most in clusters $C$ and D did not. Arbutin was degraded by most strains in clusters $B, C, D$ but not by the isolates in cluster $\mathrm{A}$.

Except for the members of cluster D, most strains examined here reduced nitrate and nitrite. These results correlated well with the ability of these strains to grow anaerobically in presence of nitrate. None of the strains grew anaerobically in Thermus medium without $\mathrm{NO}_{3}$.

The pattern of single-carbon-source assimilation was essentially similar in all strains. Several carbon sources, which included proline, glutamine, and acetate, were used by all strains. Others such as acetamide, rhamnose and L-arabinose were not utilized at all. Melibiose, raffinose and sucrose were used by the strains of the cluster $\mathrm{C}$, but most other organisms were negative for these sugars. Three strains utilized glycerol, PRQ-14 utilized glycerol and mannitol, and 'T. thermophilus' HB8 alone used D-xylose as single carbon source. Table 3 lists the most important characters for distinguishing the clusters from one another.

Of 29 other strains from world-wide terrestrial sources, only the four strains capable of growth at $80^{\circ} \mathrm{C}$ also grew in $2 \%(\mathrm{w} / \mathrm{v}) \mathrm{NaCl}$. Only two of these, ' $T$. flavus' AT-62 and ' $T$. caldophilus' GK-24 grew in $3 \%(\mathrm{w} / \mathrm{v}) \mathrm{NaCl}$.

\section{Discussion}

Most high-temperature Thermus strains have been isolated from terrestrial hot springs and artificial thermal environments. These organisms constitute one of the major aerobic heterotrophic populations at sites with $\mathrm{pH}$ $>5$ and temperatures between $55^{\circ} \mathrm{C}$ and $85^{\circ} \mathrm{C}$ (Kristjansson \& Aldredsson, 1983; Munster et al., 1985).

Several strains have also been described from shallow marine hot springs venting fresh water in Iceland (Kristjansson et al., 1986) and one strain was isolated from a site on a beach on Fiji (Hudson et al., 1989). The marine strains from Iceland were, based on the phenotypic characteristics examined, similar to terrestrial strains isolated nearby, except that the former were halotolerant.

This study demonstrates a relationship, at a low similarity level, between the marine strains from the beach at Ribeira Quente and the terrestrial halotolerant strains ' $T$. thermophilus' HB-8 and B. Strain RQ-1 was isolated from a hot spring about $5 \mathrm{~km}$ upstream from the beach sites (Santos et al., 1989), and is clearly similar to 
Table 2. Percentage of positive results for the clustered strains derived from $S_{S M} / U P G M A$ analysis and phenotypic characteristics of $T$. aquaticus YT-1, 'T. thermophilus' $H B-8, T$. filiformis and Thermus strain $B$

All strains were positive for growth at $45^{\circ} \mathrm{C}, 75^{\circ} \mathrm{C}$, the utilization of fructose, maltose, acetate, pyruvate, asparagine, glutamine, glutamate, proline and for the presence of alkaline phosphatase. All strains were negative for the utilization of L-arabinose, rhamnose, $\alpha$-ketoglutarate, acetamide and for the presence of acid phosphatase.

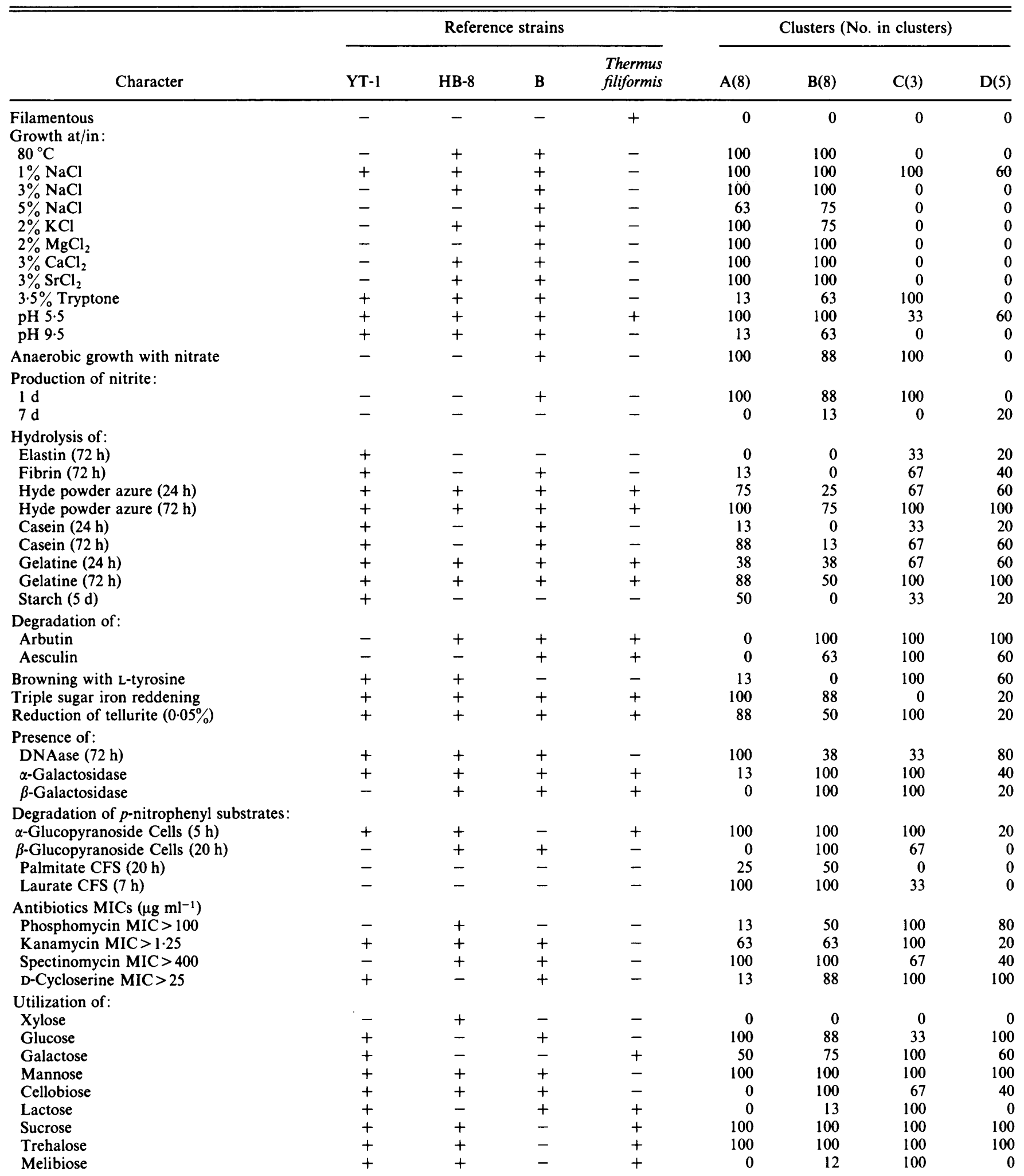


Table 2. (continued)

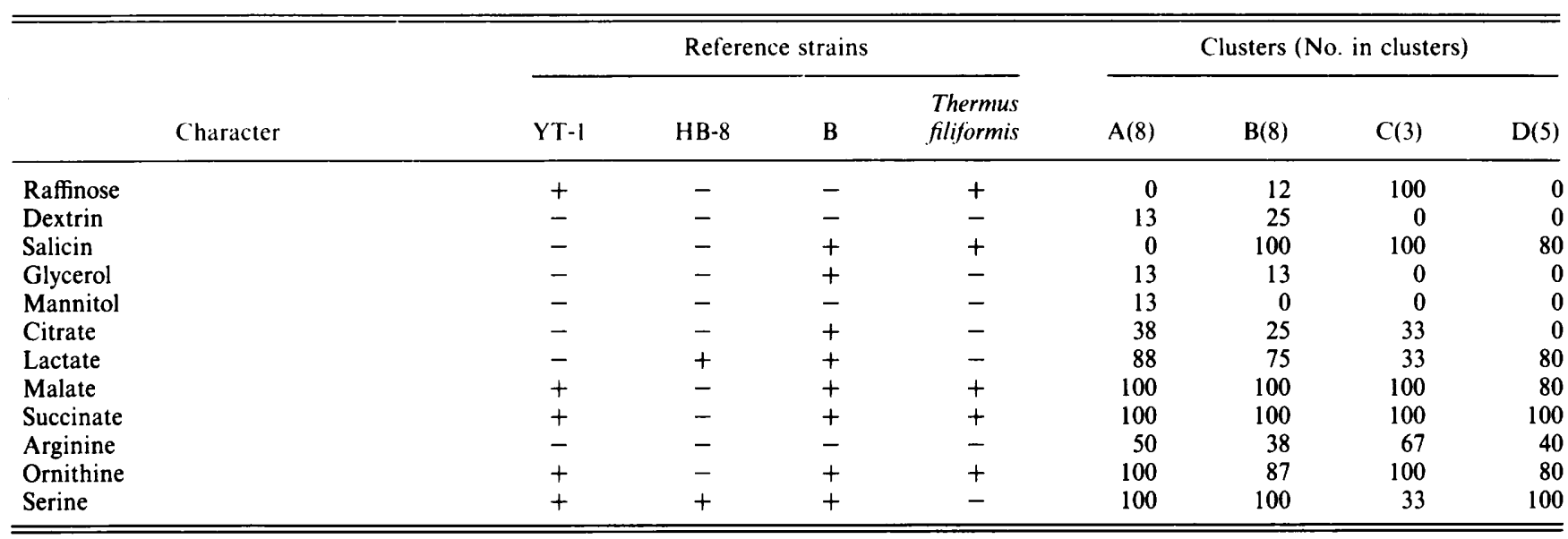

+ , Positive result or growth; - , negative result or no growth; CFS, cell-free supernatant.

Table 3. Differential characteristics of clusters

\begin{tabular}{lcccc}
\hline \hline & \multicolumn{5}{c}{ Cluster } \\
\cline { 2 - 5 } \multicolumn{1}{c}{ Character } & A & B & C & D \\
\hline Growth at $80{ }^{\circ} \mathrm{C}$ & + & + & - & - \\
Growth in $3 \% \mathrm{NaCl}$ & + & + & - & - \\
Growth in $2 \% \mathrm{MgCl}_{2}$ & + & + & - & - \\
Production of nitrite $(1 \mathrm{~d})$ & + & + & + & - \\
Degradation of arbutin & - & + & + & + \\
$\beta$-Galactosidase & - & + & + & - \\
Utilization of melibiose & - & - & + & - \\
Utilization of raffinose & - & - & + & - \\
\hline \hline
\end{tabular}

,$-<20 \%$ positive;,$+>80 \%$ positive.

the marine strains of cluster B. Other strains from hot springs at Furnas, about $7 \mathrm{~km}$ upstream, were not halotolerant and formed a separate cluster. In an earlier study, two large groups based on phenotypic characteristics were also formed; one was composed of strains from terrestrial hot springs from mainland Portugal and S. Miguel, none of which were halotolerant, and the other of the halotolerant strains ' $T$. thermophilus' HB-8, RQ-1 and RQ-3 (Santos et al., 1989).

The large degree of phenotypic diversity observed previously was affirmed here also. Geographical separation of the hot springs may explain the phenotypic diversity of clusters $C$ and $D$, but the presence of two distinct populations at the sites on the beach at Ribeira Quente must be due to other factors. The variability within the high-temperature strains of Thermus has led others to propose the existence of several species based on phenetic characteristics (Hudson et al., 1989), and genospecies based on DNA : DNA hybridization studies (Williams, 1989). It is noteworthy that ' $T$. thermophilus' HB-8, strain B and RQ-1, among others, share a very high DNA homology and may form a separate genospecies (Williams, 1989), although they clustered separately in this study.

Exchange of these halotolerant strains between nearby marine and terrestrial hot springs is probably frequent and may account for the presence of similar organisms at the beach at Ribeira Quente and a few kilometers upstream at the hot springs on the cliff by Ribeira Quente. It can be argued that terrestrial halotolerant strains would have a selective advantage in colonizing marine environments of moderate to high salinity (depending on the origin of thermal water and the degree of mixing with sea water) and would therefore predominate. Dispersion in the reverse direction would also permit the halotolerant strains to gain a foothold, all else being equal, in fresh water hot springs and establish long term populations.

This work was supported in part by the Junta Nacional de Investigação Cientifíca e Tecnológica (JNICT 87/BIO/79) and INIC (Centro de Biologia Celular). We also thank M. Manuel Donato and Genuina Flores for isolating the strains.

\section{References}

Alfredsson, G. A., Kristjansson, J. K., Huorleifsdottir, S. \& STETTER, K. O. (1988). Rhodothermus marinus, gen. nov., sp. nov., a thermophilic, halophilic bacterium from submarine hot springs in Iceland. Journal of General Microbiology 134, 299-306.

Brock, T. D. (1978). Thermophilic Micro-organisms and Life at High Temperatures. New York: Springer Verlag.

Brock, T. D. \& FreEZE, H. (1969). Thermus aquaticus gen. n. and sp. n., a non-sporulating extreme thermophile. Journal of Bacteriology 98, 289-297. 
Castenholz, R. W. (1969). Thermophilic blue-green algae and the thermal environment. Bacteriological Reviews 33, 476-504.

Fiala, G. \& Stetter, K. O. (1986). Pyrococcus furiosus sp. represents a novel genus of marine heterotrophic archaebacteria growing optimally at $100^{\circ} \mathrm{C}$. Archives of Microbiology 145, 56-61.

Huorleifsdottir, S., Kristjansson, J. K. \& Alfredsson, G. A. (1989). Thermophilic organisms in submarine freshwater hot springs in Iceland. In Microbiology of Extreme Environments and its Potential for Biotechnology, pp. 109-112. Edited by M. S. da Costa, J. C. Duarte \& R. A. D. Williams. London: Elsevier Applied Science.

Huber, R., Langworthy, T. A., Konig, H., Thomm, M., Woese, C. R., SLEYTR, U. B. \& STETTER, K. O. (1986). Thermotoga maritima sp. nov. represents a new genus of unique extremely thermophilic eubacteria growing up to $90^{\circ} \mathrm{C}$. Archives of Microbiology 144, 324333.

Hudson, J. A., Morgan, H. W. \& Daniel, R. M. (1986). A numerical classification of some Thermus isolates. Journal of General Microbiology 132, 532-540.

Hudson, J. A., MoRgan, H. W. \& Daniel, R. M. (1987). Thermus filiformis sp. nov., a filamentous caldoactive bacterium. International Journal of Systematic Bacteriology 37, 431-436.

Hudson, J. A., Morgan, H. W. \& Daniel, R. M. (1989). Numerical classification of Thermus isolates from globally distributed hot springs. Systematic and Applied Microbiology 11, 250-256.

JanNasch, H. W., Huber, R., Belkin, S. \& Stetter, K. O. (1988). Thermotoga neapolitana sp. nov. of the extremely thermophilic, eubacterial genus Thermotoga. Archives of Microbiology 150, 103-104.

Kristjansson, J. K. \& Alfredsson, G. A. (1983). Distribution of Thermus spp. in Iceland hot springs and a thermal gradient. Applied and Environmental Microbiology 45, 1785-1789.

Kristjansson, J. K., Hreggvidsson, G. O. \& Alfredsson, G. A. (1986). Isolation of halotolerant Thermus spp. from submarine hot springs in Iceland. Applied and Environmental Microbiology 52, 13131316.

LEGENDRE, L. \& LegendRe, P. (1984). La structure de donnees ecologiques. Ecologie Numerique, Vol. 2. Quebec: University of Quebec Press.

Munster, M. J., Munster, A. P. \& Sharp, R. (1985). Incidence of plasmids in Thermus spp. isolated in Yellowstone National Park. Applied and Environmental Microbiology 50, 1325-1327.

Munster, M. J., Munster, A. P., Woodrow, J. R. \& Sharp, R. J. (1986). Isolation and preliminary taxonomic studies of Thermus strains isolated from Yellowstone National Park, USA. Journal of General Microbiology 132, 1677-1683.

Pask-Hughes, R. \& Williams, R. A. D'. (1975). Extremely thermophilic Gram-negative bacteria from hot tap water. Journal of General Microbiology 88, 321-328.

Santos, M. A., Williams, R. A. D. \& DA Costa, M. S. (1989). Numerical taxonomic study of Thermus isolates from hot springs in Portugal. Systematic and Applied Microbiology 12, 310-315.

SMIBERT, R. M. \& KRIEG, N. R. (1981). General characterization. In Manual of Methods for General Microbiology, pp. 411-442. Edited by P. Gerhardt, R. G. E. Murray, R. N. Costilow, E. W. Nester, W. A. Wood, N. R. Krieg \& G. B. Phillips. Washington: American Society for Microbiology.

SNEATH, P. H. A. \& Johnson, R. (1972). The influence on numerical taxonomic similarities of errors on microbiological tests. Journal of General Microbiology 72, 377-392.

STRAMER, S. L. \& STARZYK, M. J. (1981). The occurence and survival of Thermus aquaticus. Microbios 32, 99-110.

RoLF, F. J. (1987). Numerical taxonomy and multivariate analysis for the IBM PC microcomputer (and compatibles). New York: Applied Biostatistics.

Williams, R. A. D. (1989). Biochemical taxonomy of the genus Thermus. In Microbiology of Extreme Environments and its Potential for Biotechnology, pp. 82-97. Edited by M. S. da Costa, J. C. Duarte \& R. A. D. Williams. London: Elsevier Applied Science.

Zillig, W., Holz, I., Klenk, H. P., Trent, J., Wunderl, S. JANeKovic, D., IMSEL, E. \& HAAs, B. (1987). Pyrococcus woesei, sp. nov., an ultra-thermophilic marine archaebacterium, representing a novel order, Thermococcales. Systematic and Applied Microbiology 9 , 62-70.

Zillig, W., Hol.z, I., Janexovic, D., Klenk, H. P., Imsel, E., Trent, J., Wunderl, S., ForJaz, V. H., Coutinho, R. \& Ferreira, T. (1990). Hyperthermus butylicus, a hyperthermophilic sulfur-reducing archaebacterium that ferments peptides. Journal of Bacteriology 172 , 3959-3965. 